\title{
Épocas de Consórcio de alho com Cenoura em Três Sistemas de Manejo de Plantas Daninhas, em Caçador-SC ${ }^{1}$
}

\author{
Garlic-Carrot Intercropping Times Under Three Weed Management Systems in Caçador-SC
}

\author{
MUELLER, S. ${ }^{2}$, DURIGAN, J.C. ${ }^{3}$, KREUZ, C.L. ${ }^{4}$ e BANZATTO, D.A. ${ }^{3}$
}

\begin{abstract}
RESUMO - O presente trabalho teve por objetivo avaliar os efeitos do consórcio alho e cenoura em quatro épocas de semeadura de cenoura e em três manejos de plantas daninhas, visando determinar os benefícios do consórcio em relação ao controle destas plantas, à produtividade, à rentabilidade e à sua qualidade comercial. Testaram-se quatro épocas de semeadura da cenoura $(0,15,30$ e 45 dias após o plantio do alho), combinadas a três manejos de plantas daninhas (com herbicida, sem controle e com capinas freqüentes). Utilizou-se o delineamento de blocos casualizados dispostos em parcelas subdivididas, com a época de semeadura da cenoura sendo parcela e o sistema de manejo, a sub-parcela, em quatro repetições. O oxadiazon a $750 \mathrm{~g} \mathrm{ha}^{-1}$ não foi tóxico às plantas de alho nem às de cenoura. A rentabilidade do consórcio alho e cenoura foi vantajosa em relação ao monocultivo de alho, principalmente dentro do manejo com capinas freqüentes.
\end{abstract}

Palavras-chave: Allium sativum, Daucus carota var. sativus, controle de plantas daninhas, rentabilidade.

\begin{abstract}
This work was carried out to evaluate the effect of garlic (Allium sativum) and carrot (Daucus carota) intercropping at four carrot sowing times under three weed control systems on weed control, yield, profitability and commercial quality, in Caçador-SC - Brazil. Four carrot seeding times $(0,15,30$ and 45 days after planting garlic) and three weed management systems (with herbicide, frequent manual weeding and no weed control) were tested. The experimental design was a randomized block with split-plots and four replications, with carrot seeding times being the plots and the weed management systems, the sub-plots. The herbicide oxadiazon at $750 \mathrm{~g} \mathrm{ha}^{-1}$ did not cause toxicity in the garlic, nor in the carrot plants. Garlic-carrot intercropping profitability was greater than that of garlic monoculture, mainly under frequent manual weeding.
\end{abstract}

Key words: Allium sativum, Daucus carota var. sativus, weed control, profitability.

\section{INTRODUÇÃO}

Os sistemas de cultivos consorciados baseiam-se no cultivo simultâneo, em uma mesma área, de duas ou mais culturas por um período considerável do ciclo de desenvolvimento destas (Willey, 1979). São utilizados pelos agricultores há séculos e muito comuns nos países menos desenvolvidos, sobretudo nas pequenas propriedades (Adelana, 1984; Cardoso et al., 1994).

A escolha criteriosa das culturas componentes e da época de suas respectivas instalações é de fundamental importância, para que se possa propiciar uma exploração máxima das

Recebido para publicação em 26.9.2003 e na forma revisada em 17.12.2004.

2 Eng.-Agr., D.S., Estação Experimental de Caçador-EPAGRI, Caixa Postal - 591, 89500-000 Caçador-SC; ${ }^{3}$ Eng.-Agr., Prof. Adjunto do Dep. de Defesa Fitossanitária da FCAVJ-UNESP, 14870-000 Jaboticabal-SP; ${ }^{4}$ Eng.-Agr., Prof. Adjunto do Dep. de Ciências Exatas da FCAVJ-UNESP, 14870-000 Jaboticabal-SP. 
vantagens do sistema de cultivo consorciado (Trenbath, 1975). Conforme Kreuter (1983), as espécies de alho e de cenoura são tidas como boas vizinhas ou plantas companheiras, por formarem grupos de plantas que se toleram e podem exercer efeitos benéficos mútuos.

As plantas componentes desses sistemas não são necessariamente semeadas e/ou plantadas na mesma época, porém durante apreciável parte dos seus períodos de desenvolvimento há uma simultaneidade de existência (Chagas et al., 1984). A época da semeadura escalonada das culturas componentes, nos sistemas de consórcio, é uma variável de manejo importante, mas ainda não tem sido muito estudada. O atraso de semeadura da cultura secundária pode propiciar um aumento da produtividade e uma diminuição da competição entre os fatores de crescimento (Willey, 1979).

Uma das vantagens do consórcio, que não tem recebido muita atenção, é a redução da infestação de plantas daninhas (Willey, 1979; Altieri et al., 1983). Por outro lado, a avaliação desse benefício é complexa. Ao se associar uma espécie para controlar plantas daninhas, esta provavelmente também competirá com a outra espécie consorciada. Desse modo, poderse-ia esperar que a produção das culturas seria menor do que seria se cultivadas solteiras (Horwith, 1985). Este último autor afirma que mesmo em países desenvolvidos, onde os herbicidas são bastante disponiveis, o consórcio de culturas, visando à cobertura do solo, pode ser uma alternativa econômica e ecologicamente viável.

Adelana (1984), estudando as culturas de milho e tomate, nos sistemas de consórcio e de monocultivo, em três localidades da Nigéria, constatou diferenças em termos de utilização de mão-de-obra para a realização das capinas. A necessidade de mão-de-obra foi menor, principalmente durante a segunda capina, na qual o dossel das culturas em consórcio suprimiu a maioria das plantas daninhas, pela falta de luminosidade. Em termos gerais, a supressão das plantas daninhas nos sistemas de consórcio depende, sobretudo, das culturas componentes, de suas densidades e da fertilidade do solo (Altieri et al., 1983).

Vários estudos têm sido realizados com o objetivo de comparar a eficiência técnica e econômica de sistemas de consórcio com monocultivos. Como exemplo, podem-se citar trabalhos cujos estudos envolveram culturas de tomate com milho (Adelana, 1984); algodão e alho (Parbo Jr. et al., 1989); alho e cenoura (Mueller et al., 2001); e alho e beterraba (Mueller et al., 1998). Todos esses trabalhos apresentaram rentabilidade econômica favorável ao sistema de cultivo consorciado.

O objetivo do presente trabalho foi avaliar os efeitos do consórcio alho e cenoura em quatro épocas de semeadura de cenoura e três manejos de plantas daninhas, visando determinar os benefícios do consórcio em relação ao controle de plantas daninhas, à produtividade, à rentabilidade e à sua qualidade comercial.

\section{MATERIAL E MÉTODOS}

O experimento foi realizado em campo, em Caçador-SC, tendo como coordenadas geográficas $26^{\circ} 46^{\prime} 32^{\prime \prime}$ de latitude sul e 5100'50' de longitude oeste; a altitude média no local do experimento é de $980 \mathrm{~m}$. O clima é do tipo $\mathrm{Cfb}$, ou seja, temperado, constantemente úmido (Köppen, 1948). O solo do local é classificado como Latossolo Distrófico Húmico álico, de textura argilosa (Santa Catarina, 1973). As análises para avaliação da fertilidade do solo e das características físicas da camada arável, 0 a $20 \mathrm{~cm}$, realizadas no Laboratório de Análise de Solos da EPAGRI em Chapecó-SC, revelaram os seguintes resultados: pH (água) $=7,1 ; \mathrm{pH}(\mathrm{SMP})=6,6 ;$ matéria orgânica $=4,0 \%$; $\mathrm{P}=6,0 \mathrm{ppm} ; \mathrm{K}+=256 \mathrm{ppm} ; \mathrm{Ca}+\mathrm{Mg}$ (trocáveis) = 17,2 e.mg/100 g; Al ( trocável) = 0,0 e.mg/ $100 \mathrm{~g}$; argila $=67 \%$; silte $=29 \%$; areia fina $=$ $2 \%$; areia grossa $=2 \%$; e classe textural muito argilosa.

O preparo do solo foi realizado com arado, grade e enxada rotativa. A adubação de plantio foi realizada a lanço, 10 dias antes da instalação do experimento, e constituiu na aplicação de 240 e $60 \mathrm{~kg} \mathrm{ha}^{-1}$ de $\mathrm{P}_{2} \mathrm{O}_{5}$ e $\mathrm{K}_{2} \mathrm{O}$, respectivamente, além de $10 \mathrm{t} \mathrm{ha}^{-1}$ de esterco curtido de galinhas poedeiras. Foram estudadas as culturas de alho cv. Roxo Pérola de Caçador, plantado no dia 20/07/93, e de cenoura cv. Nantes, da Agroceres, semeada nos sistemas consorciado com alho e monocultivo nos dias 20/07/93, 04/08/93, 19/08/93 e 03/09/93. 
Aos 90 dias após o plantio do alho, todas as parcelas foram adubadas com $22,5 \mathrm{~kg}$ de N, cuja fonte foi uréia.

As irrigações, por aspersão, foram feitas durante todo o ciclo da cultura, para complementar os déficits hídricos.

O controle de pragas e doenças foi efetuado a partir dos 45 dias após o plantio de alho, numa periodicidade de 7 a 15 dias para pragas e de 15 a 30 dias para doenças. Usaram-se os fungicidas à base de mancozeb, tiofanato metílico e iprodione e os inseticidas à base de deltamethrine e fenitrothion.

Para estudar o consórcio de alho e de cenoura, em relação aos respectivos monocultivos nas épocas de $0,15,30$ e 45 dias após o plantio da cultura principal (DAPCP), ou seja, do alho, utilizou-se de três manejos das plantas daninhas com: oxadiazon na dosagem de $750 \mathrm{~g} \mathrm{ha}^{-1}$ aplicados na pré-emergência do alho; nenhum controle; e capinas freqüentes. Foi utilizado o delineamento experimental de blocos ao acaso, em parcelas subdivididas, com quatro repetições. Considerou-se a época do início de consórcio como parcela e o sistema de manejo das plantas daninhas como subparcela. Cada bloco foi formado por nove parcelas, sendo quatro consorciadas, uma com monocultivo de alho e quatro com monocultivo de cenoura.

As parcelas tinham $5,525 \mathrm{~m}^{2}(1,25 \mathrm{~m} \mathrm{x}$ $4,5 \mathrm{~m})$ e as subparcelas $1,875 \mathrm{~m}^{2}(1,25 \mathrm{~m} \mathrm{x}$ $1,50 \mathrm{~m}$ ), com área útil de $1,375 \mathrm{~m}^{2}$ (cinco filas de $0,25 \mathrm{~m}$ por $1,10 \mathrm{~m}$ de comprimento) para o alho e $1,10 \mathrm{~m}^{2}$ (quatro filas de $0,25 \mathrm{~m}$ por $1,10 \mathrm{~m})$ para a cenoura.

A aplicação do oxadiazon a $750 \mathrm{~g} \mathrm{ha}^{-1}$ foi realizada um dia após o plantio de alho, estando o solo com ótimas condições de umidade. A temperatura ambiente encontrava-se em torno de $16{ }^{\circ} \mathrm{C}$. A aplicação foi feita com pulverizador costal, munido de bico 80.04, com pressão de aproximadamente $30 \mathrm{lbf} \mathrm{pol}^{-2}$, sendo o consumo de calda de 1.250 litros ha ${ }^{-1}$.

Avaliaram-se: a porcentagem de cobertura do solo pelas plantas daninhas e o número de plantas daninhas por espécie infestante aos 45, 60, 75 e 90 DAPCP; a porcentagem de controle de plantas daninhas proporcionado pelo oxadiazon, em relação à testemunha sem controle aos 45 DAPCP; os sintomas de intoxicação devidos ao oxadiazon, aos 15 e 30 dias após a aplicação deste (escala EWRC, 1964); o peso fresco das plantas daninhas por ocasião da colheita do alho (g $\left.0,1 \mathrm{~m}^{-2}\right)$; a produção de bulbos total e comercial e a classificação dos bulbos de alho, pesados após cura de 45 dias; o peso das raízes axiais tuberosas de cenoura por classe; e a rentabilidade.

Os resultados foram submetidos à análise de variância e as médias dos tratamentos foram comparadas pelo teste de Tukey (5\%). Quando não houve efeito significativo para a interação entre épocas e manejos, procedeuse ao teste de comparação de médias para tratamentos principais (épocas) e secundários (manejos), independentemente. Por outro lado, quando se detectou interação significativa, foram comparadas as médias de tratamentos principais dentro de cada tratamento secundário.

A rentabilidade dos tratamentos de consórcio e de monocultivo foi calculada descontandose custos de produção das receitas obtidas na comercialização desta. As produções foram classificadas e tiveram seus pesos multiplicados pelo preço vigente por classe. Os custos de produção, fixos e variáveis, foram calculados a partir de levantamentos realizados com técnicos da extensão rural (Instituto Cepa-SC), além dos custos observados neste experimento.

\section{RESULTADOS E DISCUSSÃO}

\section{Avaliação das plantas daninhas e seu controle e da toxicidade do herbicida às plantas das culturas componentes do consórcio}

Faz-se necessário esclarecer que as plantas daninhas foram controladas, quase que totalmente, pelas geadas até aproximadamente quatro semanas após a instalação do experimento. Assim, as avaliações das plantas daninhas iniciaram-se aos 45 dias depois do plantio e da aplicação do herbicida (DAP).

A eficiência do herbicida oxadiazon, a $0,75 \mathrm{~kg} \mathrm{ha}^{-1}$, foi mais acentuadamente observada nas avaliações realizadas aos 45 DAP (Tabela 1).

Planta Daninha, Viçosa-MG, v. 22, n. 4, p. 507-516, 2004 
Tabela 1 - Porcentagem de controle de plantas daninhas, monocotiledôneas e dicotiledôneas, pelo herbicida oxadiazon, em relação à subparcela testemunha, na avaliação realizada aos 45 DAA, no experimento de épocas de consórcio e de monocultivo (E), envolvendo alho e cenoura. Caçador-SC, 1993

\begin{tabular}{|c|c|c|c|c|c|}
\hline \multicolumn{2}{|c|}{ Cultura } & \multirow{2}{*}{$\begin{array}{c}\text { Época } \\
\text { (DAPCP) }\end{array}$} & \multicolumn{3}{|c|}{ Controle (\%) aos 45 DAA } \\
\hline Principal & Secundária & & Dicotiledôneas & Monocotiledôneas & Dicotiled. + Monocot. \\
\hline Alho & Cenoura $^{1 /}$ & & 50,0 & 0 & 0 \\
\hline Alho & Cenoura & 15 & 50,0 & 67,6 & 65,9 \\
\hline Alho & Cenoura & 30 & 84,4 & 60,8 & 67,1 \\
\hline Alho & Cenoura & 45 & 62,5 & 54,0 & 55,2 \\
\hline Alho & - & & 64,7 & 62,6 & 62,8 \\
\hline- & Cenoura & 0 & 33,3 & 43,7 & 42,9 \\
\hline- & Cenoura & 15 & 47,4 & 63,2 & 61,7 \\
\hline- & Cenoura & 30 & 0 & 44,7 & 44,3 \\
\hline- & Cenoura & 45 & 0 & 0 & 0 \\
\hline
\end{tabular}

1/ testemunha; $\% \mathrm{C}=$ porcentagem de controle em relação à testemunha infestada; DAPCP = dias após o plantio da cultura principal; DAA = dias após a aplicação do herbicida oxadiazon.

\section{Resultados para a cultura do alho}

Para as variáveis de rendimento e de seus componentes, ou seja, a produção total e comercial de bulbos, a porcentagem de bulbos comerciais, o peso médio por bulbo comercial, o número total, comercial e industrial de bulbos de alho, não houve interação significativa entre épocas e manejos. Houve efeitos significativos entre as épocas para a produção total e comercial de bulbos e peso médio por bulbo comercial. Para estas mesmas variáveis e para o número de bulbos comerciais, os efeitos foram altamente significativos entre os sistemas de manejos. Na Tabela 2 observase que, para a produção total de bulbos, a época de consórcio aos 45 DAPCP e o monocultivo de alho apresentaram as maiores médias; a época de consórcio aos 0 DAPCP, a menor; e as épocas de consórcio aos 15 e 30 DAPCP, médias que não diferiram das demais épocas de consórcio e de monocultivo. Somente quando o plantio foi simultâneo houve perda de produção de alho em relação ao monocultivo, podendose prever que o consórcio nos períodos posteriores $(15,30$ e 45 DAPCP) não diminuirá a produtividade do alho, e isso pode favorecer a rentabilidade, pois são duas - e não uma culturas a serem levadas em consideração. O manejo com capinas freqüentes proporcionou as maiores médias, e os outros dois manejos, as menores, mostrando haver efeito positivo do controle do mato para a obtenção de maiores produtividades de alho.
No que se refere à produção comercial de bulbos e peso médio por bulbo comercial, verifica-se que a época de consórcio aos 45 DAPCP apresentou a maior média; o plantio simultâneo, a menor; e as épocas de consórcio aos 15 e 30 DAPCP e o monocultivo de alho, médias que não diferiam das demais. Os dados mostram que a época de consórcio aos 45 DAPCP foi benéfica à produção de bulbos comerciais e para os pesos médios por bulbo destes, podendo-se aventar que a cenoura exerceu um efeito benéfico ao alho, o que concorda com Kreuter (1983). O manejo com capinas freqüentes apresentou as maiores médias e os outros dois manejos as menores, e isso sugere um efeito positivo do controle mais intenso para obtenção de maiores produtividades e qualidades de bulbos, podendo-se deduzir que, embora o sistema de cultivo consorciado seja reconhecido como um meio eficiente na supressão de plantas daninhas (Horwith, 1985; Adelana, 1984; Fleck et al., 1984), ele sozinho não parece ser suficiente para que se possa dispensar outros meios de controle, o que confirma os resultados de Machado et al. (1984).

Com relação ao número de bulbos comerciais por $1,375 \mathrm{~m}^{2}$, houve apenas diferenças significativas entre os manejos. O controle com oxadiazon ou com capinas freqüentes apresentou médias semelhantes entre si e superiores à apresentada pelo manejo sem controle. O não-controle das plantas daninhas diminuiu o número de bulbos comerciais de alho. 
$\mathrm{Na}$ Tabela 3 está apresentada a comparação das médias das produções de bulbos de alho, por classe, dentro das épocas e dos tipos de manejo de plantas daninhas. Salienta-se que nenhuma variável de produção de bulbos por classe apresentou interação significativa entre épocas e manejos; contudo, houve efeitos significativos entre as épocas para as variáveis pesos de bulbo nas classes 5, 4 e 3 e altamente significativos entre os manejos para as variáveis pesos de bulbos nas classes 5 e 4 .

Na comparação de médias entre as épocas, para as produções de bulbos nas classes 5 e 4, constata-se que o consórcio aos 45 DAPCP foi benéfico, assim como as épocas de consórcio aos 0 e 15 DAPCP foram para a classe 5. Isso mostra que o consórcio não diminuiu a qualidade do alho. Salienta-se que os bulbos de alho de maior tamanho ou classe têm os maiores preços.

Tabela 2 - Médias de produção, total e comercial, de bulbos de alho, porcentagem de bulbos comerciais, peso médio por bulbo comercial e industrial do experimento de épocas de consórcio e monocultivo (E), envolvendo alho e cenoura, em relação a três manejos de plantas daninhas (M). Caçador-SC, 1993

\begin{tabular}{|c|c|c|c|c|c|c|c|c|c|}
\hline \multirow{3}{*}{\multicolumn{2}{|c|}{$\begin{array}{l}\text { Causa da } \\
\text { Variação }\end{array}$}} & \multirow{3}{*}{ G.L. } & \multicolumn{7}{|c|}{ Quadrado Médio } \\
\hline & & & \multicolumn{2}{|c|}{$\begin{array}{l}\text { Produção de bulbos } \\
\qquad\left(\mathrm{g} 1.375 \mathrm{~m}^{-2}\right)\end{array}$} & \multirow{2}{*}{$\begin{array}{c}\begin{array}{c}\% \text { bulbos } \\
\text { Comercial }\end{array} \\
(\% \text { Peso })\end{array}$} & \multirow{2}{*}{$\begin{array}{c}\text { Peso } \\
\text { Médio/bulbos } \\
\text { comerciais }\end{array}$} & \multicolumn{3}{|c|}{ Número de bulbos por $1,375 \mathrm{~m}^{2}$} \\
\hline & & & Total & Comercial & & & Total & Comercial & Industrial \\
\hline \multicolumn{2}{|c|}{ Época (E) } & DAPCP $^{2}$ & \multicolumn{7}{|c|}{ Média } \\
\hline Alho & Cenoura & 0 & $783 \mathrm{~b}$ & $756 \mathrm{~b}$ & $96,1 \mathrm{a}$ & $16,1 \mathrm{~b}$ & $50,9 \mathrm{a}$ & 46,8 & $4,1 \mathrm{a}$ \\
\hline Alho & Cenoura & 15 & $857 \mathrm{ab}$ & $841 \mathrm{ab}$ & $98,2 \mathrm{a}$ & $16,9 \mathrm{ab}$ & $52,1 \mathrm{a}$ & $49,7 \mathrm{a}$ & $2,4 a$ \\
\hline Alho & Cenoura & 30 & $894 a b$ & $873 a b$ & $97,5 \mathrm{a}$ & $18,0 \mathrm{ab}$ & $51,3 \mathrm{a}$ & $48,3 \mathrm{a}$ & $2,9 a$ \\
\hline Alho & Cenoura & 45 & $1.050 \mathrm{a}$ & $1036 \mathrm{a}$ & $98,3 \mathrm{a}$ & $20,3 \mathrm{a}$ & $53,0 \mathrm{a}$ & $50,8 \mathrm{a}$ & $2,3 a$ \\
\hline Alho & & & $953 \mathrm{ab}$ & $943 \mathrm{ab}$ & $98,8 \mathrm{a}$ & $18,9 \mathrm{ab}$ & $51,3 \mathrm{a}$ & $49,8 \mathrm{a}$ & $1,6 a$ \\
\hline \multicolumn{3}{|c|}{ DMS } & 197 & 205 & 3,6 & 3,8 & 5,4 & 4,6 & 3,9 \\
\hline \multicolumn{3}{|c|}{ Manejos (M) } & \multicolumn{7}{|c|}{ Média } \\
\hline \multicolumn{3}{|c|}{ Com Herbicida } & $893 \mathrm{~b}$ & $876 \mathrm{~b}$ & $97,7 \mathrm{a}$ & $17,6 \mathrm{~b}$ & $52,3 \mathrm{a}$ & $49,6 \mathrm{a}$ & $2,7 \mathrm{a}$ \\
\hline \multicolumn{3}{|c|}{ Sem Controle } & $830 \mathrm{~b}$ & $807 \mathrm{~b}$ & $97,1 \mathrm{a}$ & $17,0 \mathrm{~b}$ & $50,6 \mathrm{a}$ & $47,3 \mathrm{~b}$ & $3,3 \mathrm{a}$ \\
\hline \multicolumn{3}{|c|}{ Com Capinas } & $999 \mathrm{a}$ & $987 \mathrm{a}$ & $98,5 \mathrm{a}$ & $19,5 \mathrm{a}$ & $52,4 \mathrm{a}$ & $50,4 \mathrm{a}$ & $2,0 \mathrm{a}$ \\
\hline \multicolumn{3}{|c|}{ DMS } & 93 & 97 & 1,7 & 1,6 & 2,6 & 2,3 & 1,8 \\
\hline
\end{tabular}

Médias seguidas da mesma letra dentro de cada grupo de médias não diferem entre si pelo teste de Tukey $(\mathrm{P}>0,05)$.

Tabela 3 - Médias dos pesos dos bulbos de alho por classe $(6,5,4,3$ e 2), do experimento de épocas de consórcio e monocultivo (E), envolvendo alho e cenoura, em relação a três manejos da comunidade infestante (M). Caçador-SC, 1993

\begin{tabular}{|c|c|c|c|c|c|c|c|c|}
\hline \multirow{2}{*}{\multicolumn{3}{|c|}{ Causa da Variação }} & \multicolumn{6}{|c|}{ Classe } \\
\hline & & & 6 & 5 & 4 & 3 & 2 & 1 \\
\hline Época (E) & & DAPCP & \multicolumn{6}{|c|}{ Peso dos Bulbos por Classe $\left(\mathrm{g} 1,375 \mathrm{~m}^{-2}\right)$} \\
\hline Alho & Cenoura & 0 & $0,00 \mathrm{a}$ & $24,25 \mathrm{~b}$ & $285,58 \mathrm{~b}$ & $337,83 \mathrm{a}$ & $108,17 \mathrm{a}$ & $26,75 \mathrm{a}$ \\
\hline Alho & Cenoura & 15 & $0,00 \mathrm{a}$ & $54,25 \mathrm{ab}$ & $328,08 \mathrm{ab}$ & $363,25 \mathrm{a}$ & 95,67 a & $15,75 \mathrm{a}$ \\
\hline Alho & Cenoura & 30 & $0,00 \mathrm{a}$ & $83,83 \mathrm{ab}$ & $413,42 \mathrm{ab}$ & $292,42 \mathrm{ab}$ & $84,00 \mathrm{a}$ & $20,33 \mathrm{a}$ \\
\hline Alho & Cenoura & 45 & $9,75 \mathrm{a}$ & $168,75 \mathrm{a}$ & $548,92 \mathrm{a}$ & $221,00 \mathrm{~b}$ & $87,87 \mathrm{a}$ & $14,33 \mathrm{a}$ \\
\hline Alho & & & $7,08 \mathrm{a}$ & $104,08 \mathrm{ab}$ & $502,58 \mathrm{ab}$ & $265,67 \mathrm{ab}$ & $63,42 \mathrm{a}$ & $10,42 \mathrm{a}$ \\
\hline \multicolumn{3}{|c|}{ DMS } & 13,96 & 117,73 & 247,35 & 106,30 & 91,93 & 24,98 \\
\hline Manejo & & & \multicolumn{6}{|c|}{ Média } \\
\hline \multicolumn{3}{|c|}{ Com herbicida } & $2,00 \mathrm{a}$ & $58,20 \mathrm{~b}$ & $417,10 \mathrm{ab}$ & $304,55 \mathrm{ab}$ & $91,00 \mathrm{a}$ & $17,15 \mathrm{a}$ \\
\hline \multicolumn{3}{|c|}{ Sem capinas } & $4,60 \mathrm{a}$ & $49,95 \mathrm{~b}$ & $332,25 \mathrm{~b}$ & $320,55 \mathrm{a}$ & $103,05 \mathrm{a}$ & $22,60 \mathrm{a}$ \\
\hline \multicolumn{3}{|c|}{ Com capinas } & $3,50 \mathrm{a}$ & $152,95 \mathrm{a}$ & $497,80 \mathrm{a}$ & $263,00 \mathrm{~b}$ & $69,40 \mathrm{a}$ & $12,80 \mathrm{a}$ \\
\hline \multicolumn{3}{|c|}{ DMS } & 11,23 & 72,66 & 96,67 & 57,25 & 43,15 & 11,25 \\
\hline
\end{tabular}

Médias seguidas da mesma letra minúscula na coluna não diferem entre si pelo teste de Tukey $(P>0,05)$.

DAPCP $=$ dias após o plantio da cultura principal. 
A produção de bulbos da classe 5 sobressaiu no manejo com capinas freqüentes; os outros dois tipos de manejo não diferiram entre si. Para a classe 4, que representa os bulbos médios, o manejo com capinas freqüentes apresentou a maior média, embora não diferisse da obtida nas subparcelas onde se aplicou o oxadiazon. Logo, o não-controle ou o controle insuficiente das plantas daninhas acarretou menor desenvolvimento das plantas de alho, o que resultou em bulbos de menor tamanho, sendo isso concordante com Shadbolt \& Holm (1956) e Hewson \& Roberts (1973).

\section{Resultados para a cultura da cenoura}

Para as variáveis produções total e comercial, número total de raízes e diâmetro de raízes de cenoura houve interação altamente significativa entre épocas e manejos. Na Tabela 4 (a), (b), (c) e (d) estão apresentadas as comparações de médias dos desdobramentos das épocas dentro de manejos e dos manejos dentro de épocas.

Pela comparação das médias de épocas dentro de manejos para as quatro variáveis, de forma generalizada, constatou-se que: a) nos manejos com oxadiazon ou sem controle houve efeito negativo da competição interespecífica sobre a cenoura, sendo ele mais evidente quando a cenoura foi semeada a partir de 30 DAPCP; b) no manejo com capinas freqüentes, salvo para o número total de raízes por $1,1 \mathrm{~m}^{2}$ e quando todas as épocas apresentaram médias semelhantes entre si, as quatro épocas no sistema de monocultivo sobressaíram, enquanto as épocas de consórcio aos 30 e 45 DAPCP mostraram as menores médias, e aquelas aos 0 e 15 DAPCP, as intermediárias. Isso sugere um efeito negativo da interferência interespecífica, principalmente quando o atraso da semeadura de cenoura foi de 30 dias ou mais; as perdas, em relação às suas respectivas épocas de monocultivo, foram em torno de $50 \%$, podendo-se deduzir que a melhor época de semeadura da cenoura neste consórcio é até os 15 DAPCP, o que assemelha em parte com Garzim (1987), o qual constatou que a melhor época de consórcio de cebola e cenoura é quando a implantação ocorre simultaneamente.

Pela comparação das médias de manejos dentro de épocas para as três primeiras variáveis, de forma generalizada, observa-se que o manejo com capinas freqüentes apresentou as maiores médias dentro de todas as épocas; no entanto, elas não diferiram das médias dos manejos com oxadiazon e sem controle dentro das épocas de consórcio e de monocultivo aos 0 e 15 DAPCP. Isso sugere um efeito negativo da interferência das plantas daninhas quando a cenoura foi semeada com atrasos maiores do que 15 DAPCP nos dois sistemas de cultivo: mono e consorciado. Entretanto, deve-se levar em conta o controle efetuado pelas geadas até aproximadamente um mês depois do plantio de alho. Logo, se este controle inicial não tivesse ocorrido, provavelmente haveria resposta da interferência das plantas daninhas já mais precocemente, principalmente para o manejo sem controle.

Quanto às produções de raízes de cenoura em termos qualitativos, somente a variável peso das raízes da classe Extra apresentou interação entre épocas e manejos significativa, mas as variáveis peso de raízes nas classes Extra AA, Extra A, Especial e Refugo não mostraram interação significativa entre épocas e manejos.

Na comparação de médias do peso das raízes (Tabela 5) da classe Extra AA, de maior valor comercial, notaram-se apenas diferenças significativas entre os manejos. A maior média foi proporcionada pelo manejo com capinas freqüentes e os outros dois manejos não apresentaram diferenças entre si; isso sugere um efeito positivo das capinas freqüentes em relação aos outros dois manejos, podendo-se inferir que as capinas freqüentes terão potencialmente maior produtividade - o que é concordante com Machado et al. (1984) - e, conseqüentemente, maior qualidade comercial.

Referente à comparação de médias do peso das raizes da classe Extra A (Tabela 5), de bom valor comercial, percebe-se que houve diferenças altamente significativas entre épocas e entre manejos. As épocas de 0 e 15 DAPCP no sistema de monocultivo mostraram as maiores médias; as épocas de consórcio aos 30 e 45 DAPCP, as menores; e as demais épocas de monocultivo e de cultivo consorciado, as médias intermediárias - isso mostra que o sistema de consórcio reduziu o peso das raízes desta classe em relação ao sistema de monocultivo, sendo essas reduções 
Tabela 4 - Comparação de médias para as variáveis: a) produção total de raízes tuberosas; b) produção comercial de raízes tuberosas; c) número total de raízes e d) diâmetro de raízes de cenoura, considerando-se o desdobramento de cada fator da interação, do experimento de épocas de consórcio e de monocultivo (E), envolvendo alho e cenoura, em relação a três manejos de plantas daninhas (M). Caçador-SC, 1993

\begin{tabular}{|c|c|c|c|c|c|}
\hline \multicolumn{2}{|c|}{ Cultura } & \multirow{2}{*}{$\begin{array}{l}\text { Época } \\
\text { DAPCP }\end{array}$} & \multicolumn{3}{|c|}{ Manejo } \\
\hline Principal & Secundária & & Com Herbicida & Sem Controle & Com Capinas \\
\hline \multicolumn{6}{|c|}{ a) produção total de raízes axiais tuberosas de cenoura $\left({\left.\mathrm{g} 1,1 \mathrm{~m}^{-2}\right)}\right.$} \\
\hline Alho & Cenoura & 0 & $4.302,0 \mathrm{bA}$ & $3.781,0 \mathrm{~b} \mathrm{~A}$ & $4.646,3 \mathrm{cdA}$ \\
\hline Alho & Cenoura & 15 & $4.296,4 \mathrm{bA}$ & $2.963,3 \mathrm{bcdB}$ & $5.065,8$ bcdA \\
\hline Alho & Cenoura & 30 & $883,8 \mathrm{cAB}$ & $394,3 \mathrm{eB}$ & $2.212,8 \mathrm{eA}$ \\
\hline Alho & Cenoura & 45 & $878,9 \mathrm{cB}$ & $1.090,7 \mathrm{deB}$ & $2.890,1 \mathrm{deA}$ \\
\hline- & Cenoura & 0 & $6.572,4 \mathrm{aA}$ & $6.324,8 \mathrm{aA}$ & $6.882,3 \mathrm{abA}$ \\
\hline- & Cenoura & 15 & $6.551,5 \mathrm{aB}$ & $6.495,8 \mathrm{aB}$ & $8.035,7 \mathrm{aA}$ \\
\hline- & Cenoura & 30 & $2.727,5 \mathrm{bcB}$ & $3.482,2 \mathrm{bcB}$ & $6.509,0$ abcA \\
\hline- & Cenoura & 45 & $2.809,8 \mathrm{bcB}$ & $1.565,8 \mathrm{cdeB}$ & $5.396,0 \mathrm{bcA}$ \\
\hline \multicolumn{3}{|c|}{ DMS Colunas $=2.157,7$} & \multicolumn{3}{|c|}{ DMS Linhas $=1.332,3$} \\
\hline \multicolumn{6}{|c|}{ b) produção comercial de raízes axiais tuberosas de cenoura $\left({\left.\mathrm{g} 1,1 \mathrm{~m}^{-2}\right)}^{2}\right.$} \\
\hline Alho & Cenoura & 0 & $3.881,9 \mathrm{abA}$ & $3.310,5 \mathrm{abA}$ & $4.039,9 \mathrm{bcA}$ \\
\hline Alho & Cenoura & 15 & $3.848,8 \mathrm{abAB}$ & $2.718,5 \mathrm{bcB}$ & $4.393,8$ bcA \\
\hline Alho & Cenoura & 30 & $742,4 \mathrm{cAB}$ & $302,1 \mathrm{~dB}$ & $1.837,2 \mathrm{dA}$ \\
\hline Alho & Cenoura & 45 & $814,9 \mathrm{cB}$ & $1.044,0 \mathrm{cdB}$ & $2.799,1 \mathrm{cdA}$ \\
\hline- & Cenoura & 0 & $5.732,5 \mathrm{aA}$ & $5.568,3 \mathrm{aA}$ & $5.590,4 \mathrm{abA}$ \\
\hline- & Cenoura & 15 & $5.433,3 \mathrm{aA}$ & $5.736,2 \mathrm{aA}$ & $6.629,0 \mathrm{aA}$ \\
\hline- & Cenoura & 30 & $2.615,7 \mathrm{bcB}$ & $3.112,1 \mathrm{bcB}$ & $5.321,5 \mathrm{abA}$ \\
\hline- & Cenoura & 45 & $2.635,1 \mathrm{bcB}$ & $1.503,6 \mathrm{bcdB}$ & $5.029,8 \mathrm{abA}$ \\
\hline \multicolumn{3}{|c|}{ DMS Colunas $=2.135,5$} & \multicolumn{3}{|c|}{ DMS Linhas $=1.374,3$} \\
\hline \multicolumn{6}{|c|}{ c) número total de raízes $\left({\left.\mathrm{g} 1,1 \mathrm{~m}^{-2}\right)}\right.$} \\
\hline Alho & Cenoura & 0 & 85 abcA & 86 abcA & $88 \mathrm{aA}$ \\
\hline Alho & Cenoura & 15 & $84 \mathrm{abcA}$ & $80 \mathrm{bcA}$ & $95 \mathrm{aA}$ \\
\hline Alho & Cenoura & 30 & $58 \mathrm{cB}$ & $37 \mathrm{~dB}$ & $86 \mathrm{aA}$ \\
\hline Alho & Cenoura & 45 & $64 \mathrm{cAB}$ & $53 \mathrm{cdB}$ & $85 \mathrm{aA}$ \\
\hline- & Cenoura & 0 & $106 \mathrm{aA}$ & $109 \mathrm{aA}$ & $91 \mathrm{aA}$ \\
\hline- & Cenoura & 15 & $95 \mathrm{abA}$ & $100 \mathrm{abA}$ & 99 aA \\
\hline- & Cenoura & 30 & 78 bcA & $92 \mathrm{abA}$ & $86 \mathrm{aA}$ \\
\hline- & Cenoura & 45 & $74 \mathrm{bcAB}$ & $56 \mathrm{cdB}$ & $80 \mathrm{aA}$ \\
\hline \multicolumn{3}{|c|}{ DMS Colunas $=28,2$} & \multicolumn{3}{|c|}{ DMS Linhas $=22,4$} \\
\hline \multicolumn{6}{|c|}{ d) diâmetro de raízes de cenoura (mm/raiz) } \\
\hline Alho & Cenoura & 0 & $31,4 \mathrm{aA}$ & $27,5 \mathrm{abcB}$ & 28,8 abc $\mathrm{AB}$ \\
\hline Alho & Cenoura & 15 & $32,0 \mathrm{aA}$ & $28,4 \mathrm{abA}$ & $30,1 \mathrm{abA}$ \\
\hline Alho & Cenoura & 30 & $24,0 \mathrm{bA}$ & $15,0 \mathrm{~dB}$ & $23,9 \mathrm{cA}$ \\
\hline Alho & Cenoura & 45 & $22,9 \mathrm{bA}$ & $21,9 \mathrm{cA}$ & $25,3 \mathrm{bcA}$ \\
\hline- & Cenoura & 0 & $32,5 \mathrm{aA}$ & $31,8 \mathrm{aA}$ & $32,8 \mathrm{aA}$ \\
\hline- & Cenoura & 15 & $32,4 \mathrm{aA}$ & $32,3 \mathrm{aA}$ & 33,4 aA \\
\hline- & Cenoura & 30 & 32,7 aA & $28,7 \mathrm{abB}$ & $32,3 \mathrm{aAB}$ \\
\hline- & Cenoura & 45 & $27,8 \mathrm{abAB}$ & $25,8 \mathrm{bcB}$ & $31,2 \mathrm{abA}$ \\
\hline
\end{tabular}

DAPCP = dias após o plantio da cultura principal; Médias seguidas da mesma letra minúscula na coluna e da mesma letra maiúscula na linha não diferem entre si pelo teste de Tukey $(\mathrm{P}>0,05)$.

mais expressivas nas épocas de consórcios, aos 30 e 45 DAPCP. Esse fato permite deduzir que o consórcio foi mais desfavorável quando iniciado aos 30 e 45 DAPCP, podendo-se prever que, para produção de raízes ainda com bom valor comercial, é interessante iniciar a consorciação em até 15 DAPCP. O manejo com capinas freqüentes sobressaiu em relação aos outros dois manejos, que por sua vez não diferiram entre si - isso sugere um efeito positivo das capinas freqüentes, podendo-se deduzir que elas proporcionaram raizes de melhor qualidade comercial, o que pode auxiliar na busca da viabilização do consórcio. 
Para o peso das raízes da classe Especial (Tabela 5), não houve qualquer efeito dentro de épocas nem dentro de manejos, o que mostra que esses fatores não exerceram qualquer influência qualitativa para esta classe.

Na comparação das médias de épocas para o peso das raízes da classe Refugo (Tabela 5), raízes não-comercializáveis, percebe-se que o sistema de consórcio em todas as épocas apresentou as menores médias e o sistema de monocultivo as maiores. Esse fato indica que o sistema de consórcio não aumentou quantitativamente o peso das raízes desta classe. Pela comparação entre os manejos para esta variável, nota-se que o manejo com capinas freqüentes apresentou as maiores médias e os outros dois manejos mostraram médias semelhantes entre si; isso parece paradoxal, pois a maior quantidade de raízes Refugo foi obtida pelas plantas em que se fez o controle de plantas daninhas mais intenso. No entanto, deve-se levar em conta a produção total de raízes já apresentada na Tabela 4(a) e relacioná-la proporcionalmente; então, verse-á que a proporção de raízes Refugo é mais ou menos constante, embora ainda um pouco maior no manejo com capinas freqüentes, quando se compara com o manejo sem controle.

\section{Análises econômicas}

Na Tabela 6 estão apresentadas as análises econômicas dos tratamentos de consórcio e de monocultivo envolvendo alho e cenoura em quatro épocas de semeadura desta em relação aos manejos com oxadiazon, sem controle e com capinas freqüentes, respectivamente.

Pelos resultados das análises econômicas referentes ao manejo com oxadiazon, verificase que os maiores lucros foram obtidos nos tratamentos aos 0 e 15 DAPCP e de monocultivo de cenoura aos 0 e 15 DAPCP; as épocas de 30 DAPCP no sistema consorciado e de 30 e 45 DAPCP no sistema de monocultivo, além do monocultivo de alho, apresentaram prejuízos.

Acredita-se que a baixa produtividade do alho foi o fator limitante; isso se deve ao fato de o cultivar usado (Roxo Pérola de Caçador) ter sido plantado um pouco tardiamente e o peso médio dos bulbilhos-semente utilizados ter sido de somente $1,34 \mathrm{~g}$, quando o ideal seria utilizar bulbilhos-semente com peso médio maior que 2,2 g. Kreuz et al. (1995) revelam que, quanto maior o nível tecnológico, para a cultura do alho, tanto maior será o lucro.

Tabela 5 - Produções médias de raízes por classe (Extra AA, Extra A, Especial e Refugo), do experimento de épocas de consórcio e monocultivo (E), envolvendo alho e cenoura, em relação a três manejos de plantas daninhas (M). Caçador-SC, 1993

\begin{tabular}{|c|c|c|c|c|c|c|c|}
\hline \multirow{2}{*}{\multicolumn{3}{|c|}{ Causa da Variação }} & \multicolumn{5}{|c|}{ Peso das Raízes/Classe $\left(\mathrm{g} 1,1 \mathrm{~m}^{-2}\right)$} \\
\hline & & & Extra AA & Extra A & Extra & Especial & Refugo \\
\hline \multicolumn{2}{|c|}{ Época (E) } & (DAPCP) & \multicolumn{5}{|c|}{ Média } \\
\hline Alho & Cenoura & 0 & 176,4 a & $1.477,1 \mathrm{~cd}$ & $1.908,9$ & $278,7 \mathrm{a}$ & $399,1 \mathrm{~cd}$ \\
\hline Alho & Cenoura & 15 & $220,1 \mathrm{a}$ & $1.569,8 \mathrm{~cd}$ & $1.347,6$ & $516,1 \mathrm{a}$ & $434,3 \mathrm{~d}$ \\
\hline Alho & Cenoura & 30 & $0,0 \mathrm{a}$ & $276,7 \mathrm{e}$ & 157,0 & $349,6 \mathrm{a}$ & $203,1 \mathrm{~cd}$ \\
\hline Alho & Cenoura & 45 & $29,9 \mathrm{a}$ & $488,8 \mathrm{de}$ & 650,0 & $384,0 \mathrm{a}$ & $67,2 \mathrm{~d}$ \\
\hline- & Cenoura & 0 & $409,7 \mathrm{a}$ & $2.754,0 \mathrm{ab}$ & $2.231,0$ & $288,6 \mathrm{a}$ & $965,3 \mathrm{ab}$ \\
\hline- & Cenoura & 15 & $787,3 \mathrm{a}$ & $3.352,8 \mathrm{a}$ & $2.121,9$ & $460,4 \mathrm{a}$ & $1.094,8 \mathrm{a}$ \\
\hline- & Cenoura & 30 & $687,3 \mathrm{a}$ & $1.732,0 \mathrm{bc}$ & 904,6 & $382,4 \mathrm{a}$ & $586,8 \mathrm{bc}$ \\
\hline- & Cenoura & 45 & $603,4 \mathrm{a}$ & $1.323,7 \mathrm{cde}$ & 864,6 & $348,1 \mathrm{a}$ & $226,3 \mathrm{~cd}$ \\
\hline \multicolumn{3}{|c|}{ DMS } & 844,4 & $1.126,1$ & 763,6 & 298,5 & 443,1 \\
\hline \multicolumn{3}{|c|}{ Manejo (M) } & \multicolumn{5}{|c|}{ Média } \\
\hline \multicolumn{3}{|c|}{ Com Herbicida } & $298,1 \mathrm{~b}$ & $1.355,4 \mathrm{~b}$ & $1.224,4$ & $343,3 \mathrm{a}$ & $416,6 \mathrm{~b}$ \\
\hline \multicolumn{3}{|c|}{ Sem Controle } & $159,4 \mathrm{~b}$ & $1.241,7 \mathrm{~b}$ & $1.170,5$ & $354,5 \mathrm{a}$ & $312,9 \mathrm{~b}$ \\
\hline \multicolumn{3}{|c|}{ Com Capinas } & $627,7 \mathrm{a}$ & $2.268,5 \mathrm{a}$ & $1.002,5$ & $431,3 \mathrm{a}$ & $761,9 \mathrm{a}$ \\
\hline \multicolumn{3}{|c|}{ DMS } & 285,0 & 348,0 & - & 117,4 & 214,4 \\
\hline
\end{tabular}

Médias seguidas pela mesma letra dentro de um mesmo grupo não diferem entre si pelo teste de Tukey $(\mathrm{P}>0,05)$. 
Tabela 6 - Rentabilidade dos tratamentos de consórcio e de monocultivo, de alho e cenoura, dentro de três manejos de plantas daninhas. Caçador-SC

\begin{tabular}{|c|c|c|c|c|c|c|c|c|c|c|c|}
\hline \multicolumn{3}{|c|}{ Tratamento } & \multirow{2}{*}{\multicolumn{3}{|c|}{$\begin{array}{c}\text { Receita } \\
\mathrm{R} \$ 1.000,00 \mathrm{ha}^{-1}\end{array}$}} & \multirow{2}{*}{\multicolumn{3}{|c|}{$\begin{array}{c}\text { Custo } \\
\mathrm{R} \$ 1.000,00 \mathrm{ha}^{-1}\end{array}$}} & \multirow{2}{*}{\multicolumn{3}{|c|}{$\begin{array}{c}\text { Lucro } \\
\mathrm{R} \$ 1.000,00 \mathrm{ha}^{-1}\end{array}$}} \\
\hline \multicolumn{2}{|c|}{ Cultura } & \multirow{2}{*}{$\frac{\text { Época }}{\text { (DAPCP) }}$} & & & & & & & & & \\
\hline Principal & Secundária & & $\mathrm{M}_{1}$ & $\mathrm{M}_{2}$ & $\mathrm{M}_{3}$ & $\mathrm{M}_{1}$ & $\mathrm{M}_{2}$ & $\mathrm{M}_{3}$ & $\mathrm{M}_{1}$ & $\mathrm{M}_{2}$ & $\mathrm{M}_{3}$ \\
\hline Alho & Cenoura & 0 & 11,68 & 10,43 & 13,11 & 9,25 & 8,97 & 9,68 & 2,44 & 1,46 & 3,43 \\
\hline Alho & Cenoura & 15 & 12,85 & 9,55 & 14,81 & 9,44 & 8,62 & 10,02 & 3,42 & 0,93 & 4,79 \\
\hline Alho & Cenoura & 30 & 7,57 & 5,68 & 11,27 & 7,91 & 7,43 & 8,91 & $-0,35$ & $-1,76$ & 2,36 \\
\hline Alho & Cenoura & 45 & 8,11 & 9,41 & 15,40 & 8,01 & 8,11 & 9,62 & 0,11 & 1,30 & 5,78 \\
\hline Alho & - & & 8,32 & 6,50 & 8,52 & 8,59 & 8,23 & 8,74 & $-0,27$ & $-1,74$ & $-0,22$ \\
\hline- & Cenoura & 0 & 10,53 & 9,61 & 11,12 & 7,71 & 7,53 & 7,99 & 2,82 & 2,08 & 3,12 \\
\hline- & Cenoura & 15 & 11,08 & 10,57 & 15,06 & 7,72 & 6,62 & 8,53 & 3,37 & 2,95 & 6,53 \\
\hline- & Cenoura & 30 & 4,96 & 5,73 & 12,33 & 6,16 & 6,40 & 7,90 & $-1,21$ & $-0,67$ & 4,43 \\
\hline- & Cenoura & 45 & 4,72 & 2,50 & 11,76 & 6,18 & 5,61 & 7,48 & $-1,46$ & $-3,11$ & 4,27 \\
\hline
\end{tabular}

DAPCP $=$ dias após o plantio da cultura principal; $\mathrm{M}_{1}=$ manejo das plantas daninhas com oxadiazon; $\mathrm{M}_{2}=$ manejo das plantas daninhas sem controle; $\mathrm{M}_{3}=$ manejo das plantas daninhas com capinas freqüentes.

Nas análises econômicas do manejo sem controle (M2), constatou-se que os maiores lucros foram obtidos nas épocas de 0 e 15 DAPCP no sistema de monocultivo. O maior prejuizo foi constatado com atraso de 45 dias no sistema de monocultivo, seguido por 30 DAPCP no sistema consorciado e pelo monocultivo de alho. Também neste manejo de plantas daninhas o fator cultivar de alho usado para esta época de plantio foi limitante.

Quanto aos resultados da análise econômica no manejo com capinas freqüentes (M3), constatou-se que somente o monocultivo de alho apresentou prejuizos, ainda que pequenos. Outra vez, como aconteceu nos outros dois tipos de manejo, ocorreu também neste, ou seja, a rentabilidade dependeu mais da cenoura do que do alho, devido principalmente aos motivos já expostos.

Concluiu-se que: o oxadiazon a $750 \mathrm{~g} \mathrm{ha}^{-1}$ não causou sintomas de intoxicação às plantas de alho nem às de cenoura; o manejo com capinas freqüentes foi o melhor, em termos de produtividade e de qualidade de bulbos de alho e rentabilidade, tanto no sistema consorciado quanto no de monocultivo; o monocultivo de alho apresentou menor capacidade competitiva com as plantas daninhas, em comparação aos tratamentos de épocas de consórcio (alho e cenoura) e de monocultivo de cenoura; o manejo das plantas daninhas com capinas freqüentes proporcionou as maiores produções de alho; o plantio simultâneo da cenoura aos 0 DAPCP proporcionou a menor produtividade de alho, e a época de consórcio aos 45 DAPCP, a maior; e o monocultivo do alho mostrou-se deficitário economicamente, porém o consórcio alho com cenoura foi rentável, principalmente no manejo com capinas freqüentes nas quatro épocas de semeadura da cenoura $(0$, 15,30 e 45 DAPCP) - nos outros dois manejos o lucro se deu nas duas primeiras épocas de consórcio (0 e 15 DAPCP).

\section{LITERATURA CITADA}

ADELANA, B. O. Evaluation of maize-tomato mixedcropping in South-Western Nigeria. Ind. J. Agric. Sc., v. 54, n. 7, p. 564-569, 1984.

ALTIERI, M. A.; LETOURNEAU, D. K.; DAVIS, J. R. Developing sustainable agroecosystems. BioScience, v. 33, p. $45-49,1983$.

CARDOSO, M. J. et al. Arranjo populacional no consórcio milho x feijão-massacar (Vigna unguiculata (L.) Walp.) em regime de sequeiro. R. Ceres, v. 41, n. 233, p. 19-27, 1994.

CHAGAS, J. M.; ARAÚJO, G. A.; VIEIRA, C. O. Consórcio de culturas e razões de sua utilização. Inf. Agropec., v. 10, n. 118, p. 10-12, 1984.

EUROPEAN WEED RESEARCH COUNCIL - EWRC Report of the $3^{\text {rd }}$ and $4^{\text {rd }}$ meetings of EWRC. Committee of methods in weed research. Weed Res., v. 4, p. 88, 1964.

Planta Daninha, Viçosa-MG, v. 22, n. 4, p. 507-516, 2004 
FLECK, N. G.; MACHADO, C. M. N.; SOUZA, R. S. Eficiência da consorciação de culturas no controle de plantas daninhas. Pesq. Agropec. Bras., v. 19, n. 5, p. 591-598, 1984.

GARZIM, A. C. Estudo preliminar sobre o consórcio entre as culturas de cebola (Allium cepa L.) e de cenoura (Daucus corota L.). Jaboticabal: Universidade Estadual de São Paulo, 1987. $45 \mathrm{p}$.

HORWITH, B. A role for intercropping in modern agriculture. BioScience, v. 35, n. 4, p. 286-291, 1985.

KÖPPEN, W. Climatologia. México: Fondo de Cultura Economica, 1948. 317 p.

KREUTER, M. L. Der bio-garten: gemüsse, obst and blumen naturegemäs angebaut. München: BLV

Verlagsgesellschaft, 1983. $400 \mathrm{p}$.

KREUZ, C. L. et al. Influência do nível tecnológico na rentabilidade da cultura do alho. Pesq. Agropec. Bras., v. 30, n. 7, p. 899-902, 1995.

MACHADO, C. M. N.; FLECK, N. G.; SOUZA, R. S. Eficiência na utilização da terra e rendimento das culturas em consórcio. Pesq. Agropec. Bras., v. 19, n. 3, p. 317-327, 1984.
MUELLER, S. et al. Épocas de consórcio de alho com beterraba perante três manejos do mato sobre a produtividade e o lucro. Pesq. Agropec. Bras., v. 33, n. 8, p. 1361-1373, 1998.

MUELLER, S. et al. Épocas de consórcio de alho com cenoura em três sistemas de manejo de plantas daninhas em Jaboticabal-SP. Planta Daninha, v. 19, p. 39-50, 2001.

PARBO JR., T. S. et al. Package of technology for garlic/ cotton relay cropping. Cotton Res. J., v. 2., n. 1/2, p. 5167, 1989.

SANTA CATARINA. Secretaria da Agricultura.

Levantamento de reconhecimento de solos do Estado de Santa Catarina. Santa Maria: Universidade Federal de Santa Catarina, 1973. 2.v.

SHADBOLT, C. A.; HOLM, M. L. G. Some quantitative aspects of weed competition in vegetable crops. Weeds, v. 4 , n. 2 , p. 111-23, 1956

TRENBATH, R. B. Diversity or be damned? Ecologist, v. 5 , n. 3, p. 76-83, 1975.

WILLEY, R. W. Intercropping - its importance and research needs. Part 1 - Competition and yield advantages. Field Crop Abstr., v. 32, n. 1, p. 1-10, 1979. 